ages, far in excess of the average; he has seen the dis. appearance of serious gastro-intestinal disease and has recorded a mortality of but .75 per cent.

To the application of physiologic principles of infant dietary, rather than to the therapeutics of infancy, the profession must look for a diminution of infant disease and a conquest over infant death.

$$
\text { DISCUSSION. }
$$

Dr. C. B. VAN Zaxt, Denver, Colo...-If the Doctor will permit I would like to add a fourth factor to the three he has so strongly presented-the matter of locality. With the quantity and quality of food and the intervals of fueding exactly the same, it is a notable fact that in different places the results of infantile feeding will be very different. It is one thing to raise a child artificially in the country and another in the city. Likewise differences will be apparent in different cities, much depending on external conditions. For a number of years I practiced in a crowded Eastern city; later on, in Denver. I am quite confident, as a result of observation, that infantile feeding is a much simpler problem in Colorado than in certain other sections and that gastro-intestinal disorders in infants, bottle fed, are much less prevalent and much less fatal here than in the East. I am not able to explain this eatisfactorily, but venture the following points as probably important: (a) an unusually good and pure milk-supply in Colorado; (b) the common, out-door life and (c) the greater freedom from microorganisms productive of fermentative changes in foods.

\section{ABSORPTION VS. DIGESTION OF MILK.}

Presented to the Section on Physiology and Dietetics at the Forty-ninth Annual Meeting of the American Medical Association. held at Denver, Colo.. June 7-10, 1898.

BY L. DUNCAN BULKLEY, A.M., M.D.

Physician to the New York Skin and Cancer Hospital; Consulting Physician to the Now Xork Hospilal, etc. NEW YORK CITY.

No words or argument are necessary to show the advantage of milk as a nutriment. Millions of human beings, from the cradle to the grave, have proved its life-giving powers, and untold millions will continue to use it, wholly ignorant of any physiologic facts concerning its mode of influencing nutrition, and guided only by instinct, which in animals is unerring, but which in man is often perverted by the elemente of civilization.

Milk is food. Alone and unassisted it is capable not only of sustaining life for an indefinite period, but it furnishes all the elements for the complete construction of the human frame; on it alone the infant learns to talk and walk, and develops all the tissues of the system. Adults have lived on it alone for weeks or months, and by it convalescents from grave sicknesses have recovered vitality and strength. Milk is a complex and delicate substance. While composed very largely of water-87 per cent. in an average good specimen-the remaining 13 per cent. contains a variety of substances wonderfully united, chemically and mechanically, in a manner suitable for absorption and appropriation by the economy. It is not the purpose of this paper to discuss the value of milk as a nutriment, nor to study its composition or chemistry, but only to present fully a practical theory in regard to the physiology of its absorption, under proper circumstances, as opposed to the commonly received notion that it must undergo digestion before it is assimilated in the system; and to this we will immediately proceed.

Some years ago a number of observers reported the intravenous injection of milk. It is not necessary here to recount the experiments and experiences, suf. fice to say that reliable men have succeeded in introducing pure milk directly into the veins of patients, where it has mingled with the blood, going first to the lungs, without any thought of digestion, such as takes place in the alimentary canal. These patients lived and throve under the process.

This intravenous injection and assimilation of milkfood first called the writer's attention to the fact that milk could be thus appropriated by the system without digestion, and led to the study and development of the theory to be propounded, and which he has put in practical application for ten or fifteen years, in hundreds and perhaps thousands of cases, and which daily experience confirms in a most substantial man. ner. I may say that the theory has been partially presented from time to time before medical societies and to friends, and also casually mentioned in writing; and while objections have been raised, these have generally been satisfactorily met and the plan proposed has been adopted successfully by very many, who, I am sure, would gladly bear witness if they were present. I may mention that the late Drs. Marion Sims and Frank Hamilton accepted the theory and acted on it during the later years of their lives, and that the late physiologist, Dr. John C. Dalton, entirely acquiesced in its correctness, and Dr. Wesley Mills, professor of physiology at McGill University, Montreal, lately acknowledged the truth of the proposition,

Recognizing that milk could enter the system without passing through stomach digestion, I began to consider under what physiologic conditions this could be effected other than by intravenous injection. An analogy to the absorption of milk was found in the chyle and its discharge into the venous blood in the subclavian vein and vena cava on its way to the pulmonary circulation. When examined microscopically the chyle is hardly to be distinguished from rich milk, and it was argued that the milk globules could pass unchanged by the same channels through which the elements of the chyle were absorbed from the stomach and intestines; the problem was to present the milk in such a manner to the absorbents that it could be taken up immediately without having it undergo the process of coagulation, caseation and subsequent gastric digestion. Remembering that the blood was alkaline, the chyle alkaline, and normal milk also alkaline, it was suggested that if the milk could be presented to the absorbents in an an alkaline state, and at a proper temperature, absorption might take place immediately without the intermediate process of digestion.

The activity of the stomach is such, as shown by the well-known experiments of Alexis St. Martin and others, that with the least excitation gastric juice is immediately poured out, which would, of course, at once coagulate some portion of the milk, and from this it would continue until all the milk was attacked, coagulated and digested. The problem was, therefore, to introduce the milk in such a manner that there should be no stomach activity and no secretion of gastric juice. Plainly then, it must be given quite apart from all solid food, or any substance or condition which could excite gastric juice. Even the least amount of acidity from a preceding meal would coagulate some of the milk and so start on the whole process of caseation and digestion.

Physiologically it is well recognized that the stomach in health does not ordinarily secrete gastric juice except under the stimulus of food At a varying period after the taking of food, the time being dependent upon the amount and quality of the food taken and the powers of digestion, the stomach has finished its task, 
absorption of certain elements has taken place, some portions have been passed on to the intestine, for further action, and the stomach is found to be $\theta$ mpty, awaiting further cause for activity. At this period the stomach loses its turgid red color, becomes paler and more or less flaccid, and its surface is bathed with more or less of an alkaline secretion, this constituting the alkaline tide. As stated, this occurs at varying periods of time after the ingestion of food; it may occur in an hour or so after a very small amount of very digestible food, or not for four, five, or even many more hours after a very heavy or unusually indigestible meal, or with very weak or sluggish diges. tion. This should constantly be borne in mind in connection with the plan of treatment to be proposed, otherwise failure is sure to result. It is only when this alkaline tide is perfectly secured and utilized that the real beneficial results of this plan can be secured.

The idea, then, is to introduce the milk, pure and alone, and at the body temperature, just after this alkaline tide has set in, or during its continuance, and to avoid food or any substance which could call forth gastric secretion until after its absorption has been fully accomplished. It is believed, then, that the warm alkaline milk is absorbed directly by the lacteals and carried at once by the thoracic duct into the subclavian vein, and so reaches the blood and is acted upon in the lungs before it is submitted to liver action.

In contrast to this stands the physiologic process which takes place when the milk is taken with other food and submitted to ordinary gastric and intestinal digestion. Here after being acted upon by the gastric and intestinal juices its casein passes through the state of proteose into peptone and thence through the portal circulation into the liver, to be transformed into urea.

It is difficult to present absolute physiologic proof of the mode of absorption of milk here claimed, as opposed to its digestion, under the circumstances detailed, but strongly corroborative evidence is furnished in some experiments made by Dr. Andrew H. Smith of New York, who has kindly consented to my mentioning them. Some years ago, while experimenting on kittens to determine certain facts in regard to blood pressure, he accidentally wounded the jugular vein. To his surprise, the blood from it appeared of a lighter color than expected, and in marked contrast to that obtained from the saphenous vein. Taking another kitten from the mother's breasts he opened the jugular vein and found the same condition, and, I believe, he did the same with a third nursing kitten. He says that he could never explain the phenomenon until I propounded to him the theory of milk absorption, in full, which he at once accepted and regarded as an explanation of the condition found in the kittens; the milk being absorbed at once by the lacteals was poured by the thoracic duct into the subclavian vein and found ready exit on the opening of the jugular. I remarked to him that he had supplied the one missing link in support of my theory. It would be interesting to test the condition of the stomach, after taking milk on this plan. by means of the stomach-tube, but possibly this procedure might of itself excite gastric activity, which would confuse matters and vitiate the value of the experiment.

It would lead us too far from the practical object of this paper to attempt to enter at all fully into the physiology of digestion and assimilation or to elaborate any of the physiologic chemistry of the subject. Suffice to say that this difference in the course which milk can take under varying circumstances becomes clearly evident, clinically and practically, with close and sufficient observation. Proof could be furnished by hundreds of cases in which the present writer has carefully directed this plan of taking milk and has observed and recorded the facts, Constantly those who have been quite unable to use milk in the ordinary way, have followed the plan proposed, with the most satisfactory results. In the writer's own person, milk taken in the ordinary manner and with food invariably disagrees, causing sick headache and functional liver disturbances, whereas, following the plan proposed, he has taken a quart of milk daily for ten and more years with the greatest benefit.

A few words may be added in regard to the practical features of the subject. It has constantly happened to the writer that patients have returned, after full directions had been given, as was believed, with the statement that the plan was not successful, and that it was impossible for them to take milk, as had always been the case. In some instances undoubtedly there may be such an aversion to milk, or such an idiosyncrasy in the patient, that even this plan does not succeed. But almost invariably it has been found that the want of success was due to some failure in carrying out the plan proposed; for it must be clearly understood and most strongly and forcibly declared that unless the theory is perfectly acted upon and the plan absolutely carried out as to all its details, the results claimed can not be expected. But after an experience with it of ten or fifteen years, and with the most varied and often difficult class of patients, and with many temporary failures, I again assert that when perfectly carried out results can be obtained which are of the greatest and most lasting benefit; there is hardly a single fact in medicine or feature in therapeutics of which I am more confident. It is sometimes difficult, however, to succeed at first in getting patients to carry out the plan exactly, for it must be remembered that the smallest possible amount of gastric juice or acidity will cause some portion of the milk to be coagulated; and when this digestive process is once begun, even in the slightest degree, it must go on until all the milk has been attacked and digested.

In many instances I have found that patients had taken with the milk a small amount of food, as a cracker, following the advice of a former physician or that of friends. Again, some will put an egg in the milk, or add whisky or brandy, and in many ways I have had the correct operation of the plan interfered with. It repeatedly happens that the milk is taken too soon after a meal, or perhaps even when a long enough interval of time has elapsed, it has happened that owing to a sluggish digestion, it has come upon the products of a former meal, and not during the alkaline tide. Thus, patients will often take milk at half-past ten or eleven in the morning or at three or four in the afternoon, because at that time they had felt a faint and "gone feeling" and mistook the uncomfortable sensation of delayed digestion for hunger. It will, therefore, often be very d:meult to be sure that the stomach has reached the alkaline condition, when only the milk can be taken with advantage. My rule is not to have it taken longer than an hour before the coming meal, but under proper conditions it may often be taken 
even up to thirty minutes before eating, although this is rare.

Sometimes, if the digestion is sluggish, it is necessary to administer pepsin or other digestives very freely and repeatedly, to secure an empty stomach early enough; and at times when there is any doubt, I have taken one or more doses of bicarbonate of soda half an hour or so before taking the milk. It is also often advantageous to put a little bicarbonate of soda in to the milk, if there is any question as to its perfect alkalinity or as to the alkaline state of the stomach. But these measures will not be successful if there is food or any remains of an acid digestion.

The temperature of the milk is also an element of importance. If taken iced cold the perfect action of the plan is frequently interfered with; the effort to warm the milk in the stomach, which is necessary before absorption, will often seem to give occasion for an attempt at stomach digestion, and a sensation of pressure and discomfort will follow, which is far different from the agreeable sensations accompanying its proper use. My directions, therefore, are that the milk shall be made of the body temperature, by heat. ing it carefully in hot water, if possible; if boiled so as to produce the slightest scum on the surface, and this is taken, it acts prejudicially by exciting gastric action, and the aim of the process is defeated. It is often desirable to warm the milk by the addition of hot water, as absorption is even more readily affected thus than when the milk is too rich and thick.

I have also often seen harm done when cream had risen, and had been stirred into the milk, forming flakes; these small solid particles being incapable of immediate absorption may result in causing the secretion of gastric or pancreatic fluid in the process of digestion.

Many of these points--and more could be mentioned-may seem trivial and annecessary, but long experience in following the plan proposed under the most diverse circumstances has convinced me that in this, as in so many other medical matters, attention to details is of the utmost importance; and, as reiterated here more than once, it is essential that the plan be perfectly followed in every detail, in order to obtain perfect success.

When prescribing milk according to the plan proposed, pure, warm and alone, one hour before meals, patients often object that it would destroy what appetite they have. But it is an interesting fact, based on physiologic reasons, that when thus taken successfully it not only does not impair the appetite, but greatly increases it. If a particle of food, as a cracker, is taken with it, or if for some reason or fault it does not act exactly rightly, then the appetite is impaired; naturally so, because there is a process of digestion which takes a longer time than the hour, or rather half hour required for its absorption, and the stomach can not be ready for fresh food again so soon.

The physiologic basis for the improvement of the appetite is simple. The process of secretion from the glands of the stomach and elsewhere, depends largely upon osmosis and blood pressure. By the quick absorption of milk the pressure of the blood in the capillaries is increased, and a richer blood is offered for the secretion of the gastric juice. This improvement in the appetite under this plan of treatment has been observed by myself and others in dozens of instances.

A common time of administering milk with me, especially in poorly nourished females, is in the morning, one hour before breakfast, the directions being that the patient shall lie still for a quarter of an hour thereafter; it is often found then that instead of rising fatigued, with no appetite for breakfast, the patient gains in strength and enters on the day with a vigor quite unknown before. I also very commonly have weak females lie down in a darkened room for a half-hour nap after taking the milk at 12 and 5 o'clock. I could give many, many instances where the transformation of the patient by this simple procedure has been really marvelous. The soporific qualities of warm milk at bedtime or in the night are sometimes remarkable.

I trust I may be pardoned for my seeming enthusiasm in regard to the plan proposed, for it is presented after mature thought and very extensive experience, dating back many years; and I only wish to make this theory and plan so clear and plain that many may be led to adopt it in daily practice, feeling sure that if properly understood and faithfully carried out their experience will be the same as mine and that of many other physicians who have accepted and worked. upon it.

\section{East Thirty-seventh Street.}

Discussion.

Dr. Robert H. Babcock, Chicago-I desire to add my testimonial to the efficacy of milk taken in accordance with Dr. Bulkley's method. Since having learned of this way of drinking milk two years ago, I have so prescribed it to many patients, and with but one exception, I think, they have experienced no difficulty in its assimilation. On the contrary, it has been well borne, and, what was almost incredible to me at first, it has been found not to interfere with appetite for, and digestion of, the following meal. I am at a loss to explain why milk taken in this manner should agree better and apparently be absorbed or assimilated differently from when drunk at meal-time, but I am convinced that some difference does exist. So firmly rooted are the teachings of physiology in my mind that I am not able to accept Dr. Bulkley's explanation of its absorption directly, as unaltered milk. It may be that being bland and warm the milk is allowed by the empty stomach to pass through into the duodenum; but how it can escape the action of the milk-curdling ferment of the pancreatic secretion, I can not understand. Of course, the cream, or fat of the milk can be taken up by the lacteals at once, since it is already in a state of fine emulsion, while the water and the salts in solution might be quickly and directly absorbed; but I confess I can not understand, as yet, what is done with the casein if it is not subjected to digestion in the small intestine. However, my failure to understand the mechanism of 'its digestion, or absorption without digestion, offers no barrier to my acceptance of its clinical value when taken in the manner devised by the distinguished author of the paper.

Dr. H. W. SCaIF'E, Chicago-My objection to Dr. Bulkley's theory is this: He asks us to believe milk is absorbed by the lacteals as water would be by a sponge, and is conveyed to the veins unchanged. His theory is entirely groundless; his idea of assimilation old-fashioned. The walls of the intestines do not act like inanimate membrane. "The act of seizing food," says Binel, "belongs to living tiseue. It is not a chemic nor a physico chemic, but a physiologic phenomena." So it is entirely inadmissible, that by his method of administration or any other method, milk can pass through the living tissue without change. His clinical facts are good, his theory to explain which is entirely false, and if he injects milk into the veins of any animal, he will not feed it, but kill it.

Dr. C. B. VAN ZANT, Denver-Dr. Bulkley's paper, based as it is, upon such a large amount of clinical experience, the value of the method which Dr. Bulkley advocates, can not be gainsaid. With his theoretic explanation, however, of the physiology of this process we must heartily disagree. It is contrary to all the present teachings of physiology to suppose that milk can gain access to the blood-current unchanged and without previous coagulation and digestion. In the first place, we can not believe that milk in any form, or temperature, or in any manner of administration will fail to evoke an outpouring of gastric juice. The experiments of Beaumont showed that it
invariably follows the ingestion of fluids, and even the gentlest 
titillation of the gastric mucous membrane led to its discharge. If this be true, coagulation of the milk in the stomach is certain, no matter when or how the milk be given. lf, however, we grant the possibility of the milk running the gauntlet of gastric juice coagulation and a partial digestion, what assurance have we that it would fail to excite the pancreatic secretion, by which it would inevitably be coagulated and digested? It seems to me totally untenable to suppose that the milk can enter the absorbents directly and without change. While I gladly admit that the method of milk administration which Dr. Bulkley advocates seems to have the weight of clinical experience back of it and to be valuable, the theory as to its action seems to me out of accord with the present accepted beliefs of the best physiologists.

Dr. BULKLEY, in closing, said he was glad of the criticisms which had been made, as he believed that only by frank and full discussion could truth be brought out. He had purposely presented the paper before the Section on Physiology because he wanted the theory proposed to be scientifically considered and criticised, and he should endeavor to benefit by the re. marks made, and should study the subject still further.

But he would say that in spite of the objections that had been raised he should still adhere to theory as proposed until a better working hypothesis was obtained. Because, however the ultimate course of the milk may be considered physiologi. cally, there was somehow a vast difference, greater than he could express by words, between the behaviour of milk when taken in the ordinary way carelessly, or with food, and when administered absolutely according to the principles and meth ods laid down. This clinical difference, which he had observed for many years - from ten to twenty - and in hundreds of in stances, must have some scientific reason back of it; and, for his part, he would prefer to accept the accumulated evidence of years as demonstrating some physiologic difference than accept the statements or arguments that had been brought forward to show that the theory was untenable. Possibly the physiology was wrong -. for this is a somewhat changing science and we can not explain just how milk or indeed other aliments act under perfectly normal conditions, for it is to be remembered that experiments, on which physiology is based, always introduce an abnormal element themselves. He should, therefore, adhere to his theory as an excellent working basis, because it furnished the means of aiding in carrying out intel ligently the system or plan described, which with him and others had yielded such exceptionally beneficial results.

WHAT IS THE FOOD VALUE OF ALCOHOL?

Presented to the Section on Physiology and Dietetics, at the Forty-ninth Annual Meeting of the American Medical Association, held at Denver, Colo., June 7-10, 1898.

BY E. STUVER, M.Sc., M.D., Pн,D.

Member Colorado State Medical Society (Vice-President 1894); Rucky Mountain Inter-State Medical Association; American Medical Association; International Medical Congress, etc.

RAWLINS, WYo.

Food is described by the Standard Dictionary as: "That which is eaten or drunk, for nourishment, aliment; nutriment in the scientific sense; any substance that being taken into the body of animal or th plant, serves through organic action to build up normal structure or supply the waste of tissue, nutriment; aliment as distinguished from condiment;" and Webster gives substantially the same definition

While these definitions give what I desire to designate as the positive side of the question, there is also a negative side which should be considered in arriv. ing at a true estimate of the food value of any substance ingested by man or animals for the purpose of nutrition. By this negative side I mean that the food substance, while containing the elements necessary for tissue-building or heat-production, should not interfere with the normal organic processes of digestion, assimilation or excretion. Nor should it interfere with the normal oxygen-carrying power of the red-blood corpuscles or impair the healthy activity of the enveloping membrane which surrounds all the tissues and cells of the body, and on whose unimpaired dialyzing power the endosmosis of nutrient material and the exosmosis of broken-down, retrograde products or toxins depend. As you are all well aware, recent investigations have demonstrated the immense importance of auto-intoxication and the very serious consequences that may result from re. tained toxins or waste materials. On this subject Dr. Thomas Oliver speaks as follows: "Bouchard ${ }^{1}$ clearly indicates to us that man is constantly standing, as it were, on the brink of a precipice; he is continually on the threshold of disease. Every moment of his life he runs the risk of being overpowered by poisons generated within his system. Self-poisoning is only prevented by the activity of the excretory organs, chiefly the kidneys, and by the watchfulness of the liver, which acts the part of a sentinel to the materials brought to it by the portal vein from the alimentary canal.

In view of these facts free elimination assumes a very important place and must receive careful consideration in arriving at conclusions concerning the relative value of nutrient materials. We should inquire, not only as to the tissue-forming or heat-producing power of any particular food substance, but also ascertain how it affects digestion, assimilation and excretion, and then we will be in a position to arrive at a true estimate of its value to the system. On this basis, let us now try to ascertain the food value of alcohol. I shall confine what I have to say to ethylic alcohol $\left(\mathrm{C}_{2} \mathrm{H}_{5} \mathrm{HO}\right)$, the kind in common use.

Ever since the earliest historic times until within recent years, it has been believed that alcohol is a true tonic; that it stimulates mental activity, increases muscular force and the powers of endurance; that it enables man better to endure the rigors of extreme cold and the fervor of intense heat than he could without it; that it protects him against the invasions of disease and helps him to counteract their effects and throw them off when contracted--in short, that it elevates his thoughts, increases his powers, blunts his pains and sorrows and enhances his joys. Even twelve or fifteen years ago it was believed by many eminent authorities that pure alcohol possesses a positive food value. T. Cranstoun Charles "says: "As to the rôle played by alcohol in the economy there is still some difference of opinion, but the weight of evidence is in favor of the theory that it acts more or less as an aliment. When ingested in excess much of it traverses the system unburnt and is then found in the urine, sweat and expired air (Lallemand, Perrin, etc.); but when taken in a moderate dose the umount eliminated by the urine forms but a small proportion of that absorbed (Dupre); some even maintain that the quantity thus excreted does not amount to more than 0.7 per cent. (Thresh). The chief portion of the alcohol in the latter case, therefore, undergoes consumption in the body (Anstie, Thudicum, Schulimus, Baudet, etc.). We shall see elsewhere that a little alcohol is generated in the organism itself (Bechamp). Alcohol does not appear to increase the production of heat as a chemic agent (E. Smith), rather, in large amount, lowering temperature by checking some of the oxidation occurring in the body, particularly when abnormal, as in fevers. It also, when given in a state of health, tends to diminish muscular power, but indirectly the effect may be to increase it by improving the tone of the system

1 Bouchard: Preface to "Auto-Intoxication in Disease," page 8.

2 Elements of Physiologic and Pathologic Chemistry, 1884. 